\title{
Analysis Design and Implementation of Soft Single Switched Boost Converter
}

\author{
P.Hemachander \\ EEE Department \\ RGCET, Pondicherry-65011 \\ India
}

\author{
Dr.P.Ajay-D-VimalRaj \\ Assistant Professor \\ EEE Department \\ PEC, Pondicherry-65014 \\ India
}

\author{
Dr.M.Sudhakaran \\ Associate Professor \\ EEE Department \\ PEC, Pondicherry-65014 \\ India
}

\begin{abstract}
This paper proposes a better family of PWM soft single switched (SSS) Boost converter topology with low voltage and current stresses in switches. Soft switching condition is carried out through single switch. In most of the converter topologies under zero current condition (ZCS) only the switch is triggered to on mode and switch is made to off mode under zero voltage condition (ZVS).In a prototype model for soft turn on and turn off switch is applied to a boost(PWM) SSS converter, The operating principle of the converter topology is analyzed and its operating modes are studied .The experimental results of a prototype boost converter is compared with the theoretical analysis.
\end{abstract}

\section{Keywords}

Pulsewidth modulation (PWM), soft-single switched (SSS), zero-current switching (ZCS), zero-voltage switching (ZVS).

\section{INTRODUCTION}

Conventional hard switching converters posses increased size, weight, increased switching losses and electromagnetic interference. The switching devices used in DC converters with Pulse Width Modulation (PWM) control can be gated to synthesize desired shape of output voltage or output current at turn on and turn off conditions of switch. However the devices were turned on and off at a load current with high di/dt value. The switches were subjected to an high voltage stress and the switching power loss of device increases linearly with the switching frequency. The turn on and turn off loss could be a significant part of the total power loss. In order to solve the above issues soft switching converters are the need of the hour .

In recent years many research work were carried out in modernizing soft switching topologies in DC-DC converters. Soft switching converters are easy to control the output voltage to desired magnitude by Pulse Width Modulation (PWM) technique. Among the converter topologies quasi resonant converter topologies does not have extra switches to obtain soft switching conditions. They have major drawback of variation of the switching frequency [1].The complexity of power and control circuit was increasing under zero voltage transition and zero current transition constituting PWM based control by usage of two switches to achieve soft switching [3-10].

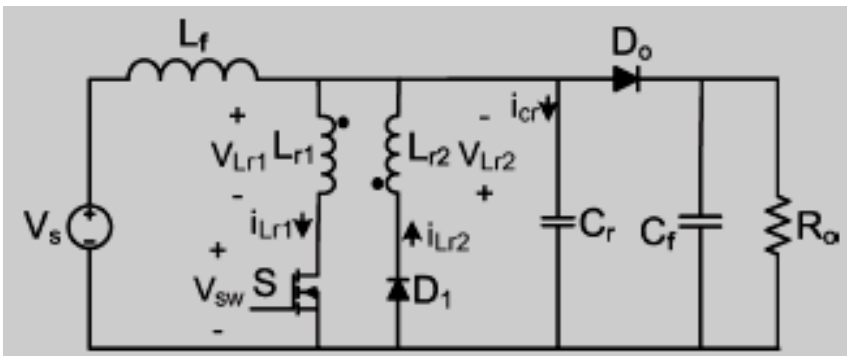

Fig. 1. SSS Boost Converter

The analysis and experimental results of an buck quadratic PWM soft switching converter and improved Boost PWM soft single switched converter with single switch were presented in [10-12] but voltage stresses and current stresses is more vulnerable in switches.PWM based SSS converters provide a solution to the problems faced by converter topologies [11-13]. An improved version of boost PWM SSS converter with low voltage and current stresses have been adopted to overcome above drawbacks but usage of large number of passive components make the converter implementation difficult [14].

The operation and properties of ZCT-PWM were compared with other converter topologies and discussed in [15]. A systematic approach to developing soft switching PWM converters based on synchronous switch is presented in [16]. A novel method is applied to isolated converters topologies this method provide soft switching condition for all the switching elements [18]. A novel family of pulse width modulation soft single switched $\mathrm{dc}$ -dc converter without high voltage and current stresses is been described.

In this paper pulse width modulation based SSS converter having reduced the voltage and current stresses were presented. The switch in experimental set up is turned on under zero current switching (ZCS) and turned off under zero voltage switching (ZVS) .The converter main diode turns on under ZVS condition turns off under zero voltage zero current switching (ZVZCS) conditions. Furthermore auxiliary diode turns on ZVS condition and turns off under ZCS .In this paper PWM SSS converter with boost converter were analyzed and its operating modes are described in section II.A general design consideration are elaborated in section III. The simulation results with boost converters were analyzed in sectionIV. 


\section{CIRCUIT ANALYSIS DESCRIPTION AND FOR BOOST CONVERTER}

The circuit components of boost converter were shown in Fig2.The circuit components namely $\mathrm{L}_{\mathrm{r} 1}, \mathrm{~L}_{\mathrm{r} 2}, \mathrm{D}_{1}$ and $\mathrm{C}_{\mathrm{r}}$ were added to the conventional boost converter. The Filter inductor $\left(\mathrm{L}_{\mathrm{f}}\right)$ and Filter capacitor $\left(\mathrm{C}_{\mathrm{f}}\right)$ were large enough and to be replaced by current source $\left(\mathrm{I}_{\mathrm{in}}\right)$ voltage source $\left(\mathrm{V}_{0}\right)$ respectively. It is assumed that all circuit components all ideal. The non ideal effects of leakage inductance of the coupled inductors were discussed in section IV. The turns ratio of coupled inductor is $\mathrm{N}_{2} / \mathrm{N}_{1}$, Thus $L_{r 2}=n^{2} * L_{r 1}$.

The Boost Converter topology has six distinct operating modes in a switching cycle are illustrated Fig2
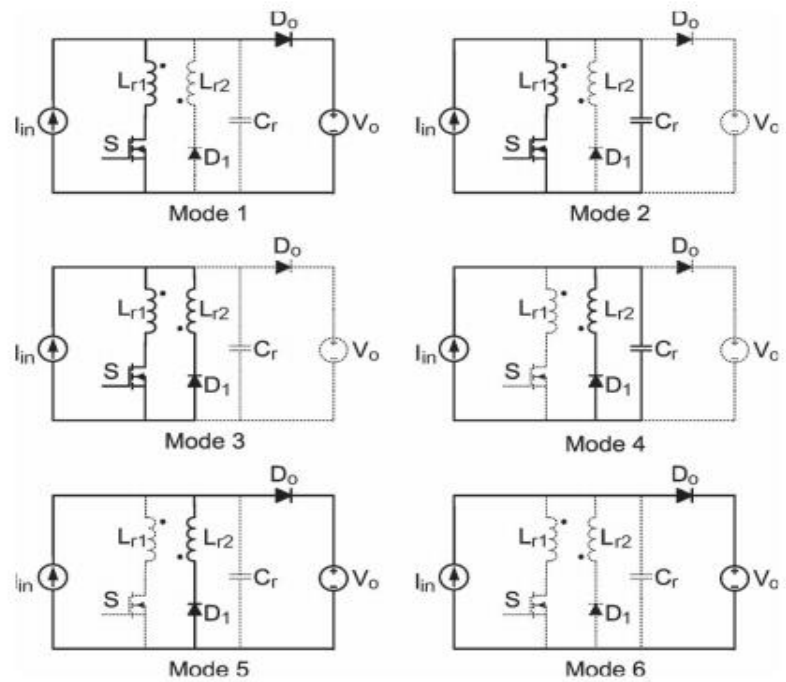

Fig. 2. Equivalent modes of the boost converter

Mode1 $\left[\mathrm{t}_{0}-\mathrm{t}_{1}\right]$ :Assuming that main switch off, and $\mathrm{I}_{\text {in }}$ current flows through the diode $\left(\mathrm{D}_{0}\right)$ and capacitor $\left(\mathrm{C}_{\mathrm{r}}\right)$ voltage is equal to output voltage $\left(\mathrm{V}_{0}\right)$.At $\mathrm{t}_{0}$, under $\mathrm{ZCS}$ condition the switch is turned on due to series inductor $\mathrm{L}_{\mathrm{r} 1}$. The inductor current is [2]

$$
\begin{gathered}
V_{0}=\mathrm{L}_{\mathrm{r} 1} \frac{d I_{\text {in }}}{d t} \\
d I_{\text {in }}=\frac{V_{0}}{L_{r 1}} * d t
\end{gathered}
$$

The inductor current is

$$
I_{l r 1(t)}=\frac{V_{0}}{L_{r 1}} * t_{1}-t_{0}
$$

At $t_{1}, I_{1 r 1}$ reaches $I_{\text {in }}$, therefore, duration of this mode is

$$
\Delta t_{1}=t_{1}-t_{0}=\frac{L_{r 1} I_{i n}}{V_{0}}
$$

Mode $2\left[\mathrm{t}_{1}-\mathrm{t}_{2}\right]$ : At the instant $\mathrm{t}_{1}$, current through the inductor $\mathrm{L}_{\mathrm{r} 1}$ has reached $I_{\text {in }}$ and current through diode $D_{0}$ has reached zero.
And it makes the diode $\mathrm{D}_{0}$ turns off is under ZCS. Due to existence of capacitor connected in parallel with diode voltage across rises slowly and it is considered as ZVS. Therefore diode $\mathrm{D}_{0}$ turnoff is ZVZCS .During mode2, inductor $\mathrm{L}_{\mathrm{r} 1}$ starts to resonate with capacitor $\mathrm{C}_{\mathrm{r}}$. The resonant capacitor voltage and resonant inductor current are [2]

$V_{s}=L \frac{d i}{d t}+\frac{1}{C} \int i d t$

Take Laplace transform for equation (5), we get that

$$
\begin{aligned}
& \frac{V_{s}}{S}=L S I(S)-I(0)+\frac{1}{C}\left[\frac{I(S)}{S}+\frac{q(0)}{S}\right] \\
& I(0)=0
\end{aligned}
$$

For an inductor $V_{c}(0)=0$, or $q(0)=0$

$$
\begin{aligned}
& I(S)=\frac{V_{s}}{S\left[L S+\frac{1}{C S}\right]} \\
& I(s)=\frac{V_{s}}{\left[L S^{2}+\frac{1}{C}\right]} \\
& I(S)=\frac{V_{s}}{L\left[S^{2}+\frac{1}{C L}\right]}
\end{aligned}
$$

Let $\omega_{0}=\frac{1}{\sqrt{L^{*} C}}, \omega_{0}^{2}=\frac{1}{L C}$, It gives

$I S=\frac{V_{S}}{L S^{2}+\omega_{0}^{2}}$

$I \quad s=\frac{V_{s}}{L} * \frac{1}{\omega_{0}} * \frac{\omega_{0}}{S^{2}+\omega_{0}^{2}}$

$\omega_{0}=\frac{1}{\sqrt{L C}}$

$I S=V_{s} * \sqrt{\frac{C}{L}} * \sin \omega_{0} t$ 


$$
\begin{aligned}
& Z_{0}=\sqrt{\frac{L_{r 1}}{C_{r}}} \quad Z_{r}=\sqrt{\frac{L_{r 1}}{C_{r}}} \\
& I_{c}=\frac{V_{0}}{Z_{r}} \operatorname{Sin} \omega_{r}\left(t_{2}-t_{1}\right) \\
& V_{c}=\frac{1}{C} \int_{t 1}^{t 2} V_{0} * \sqrt{\frac{C}{L}} * \sin \omega_{r} t \\
& V_{c r}(t)=V_{0} * \operatorname{Cos} \omega_{r}\left(t_{2}-t_{1}\right) \\
& I_{l r 1} \quad t=I_{\text {in }}+I_{c} \\
& I_{l r 1}(t)=I_{\text {in }}+\frac{V_{0}}{Z_{r}} \operatorname{Sin} \omega_{r}\left(t_{2}-t_{1}\right)
\end{aligned}
$$

This mode ends capacitor voltage $\left(\mathrm{V}_{\mathrm{cr}}\right)$ reaches zero. Thus duration of this mode is

$$
\Delta t_{2}=t_{2}-t_{1}=\frac{\Pi}{2 \omega_{r}}
$$

Mode3 $\left[\mathrm{t}_{2}-\mathrm{t}_{3}\right]$ : When capacitor voltage $\left(\mathrm{V}_{\mathrm{cr}}\right)$ reaches zero, diode $\mathrm{D}_{1}$ start to conduct under ZVS condition due to existence of capacitor $C_{r}$. Since capacitor voltage $\left(V_{c r}\right)$ reaches zero [2]. Since ampere turns of $\mathrm{L}_{\mathrm{r} 1}$ and $\mathrm{L}_{\mathrm{r} 2}$ should remain constant.

$$
\begin{aligned}
& \left(I_{i n}+\frac{V_{0}}{Z_{r}}\right) N_{1}=I_{L r 1} N_{1}+I_{L r 2} N_{2} \\
& \left(I_{i n}+\frac{V_{0}}{Z_{r}}\right) N_{1}=I_{i n}+I_{L r 2} N_{1}+I_{L r 2} N_{2} \\
& I_{i n} N_{1}+\frac{V_{0}}{Z_{r}} N_{1}=I_{i n} N_{1}+I_{L r 2} N_{1}+I_{L r 2} N_{2} \\
& I_{i n}\left(\frac{V_{0}}{Z_{r}}\right) N_{1}=I_{L r 2}\left(t_{2}\right) N_{1}+N_{2} \\
& I_{L r 2} t_{2}=\frac{V_{0}}{Z_{r}}\left(\frac{N_{1}}{N_{1}+N_{2}}\right) \\
& \frac{N_{2}}{N_{1}}=n
\end{aligned}
$$

In Inductor, $\mathrm{L}_{\mathrm{r} 1}$ current is equal to the sum of input current and current in the $\mathrm{L}_{\mathrm{r} 2}$.From this following equations are obtained.

$$
I_{L r 1} t_{1}=I_{\text {in }}+I_{L r 2} t_{2}
$$

$$
\begin{array}{ll}
I_{L r 1} & t_{1}=I_{i n}+\frac{V_{0}}{n+1 Z_{r}} \\
I_{L r 2} & t_{2}=\frac{V_{0}}{n+1 Z_{r}}
\end{array}
$$

The interval of this mode 3 and mode 2 is called converter duty cycle .This mode ends when the switch is turned off. The duration of this mode is

$$
\Delta t_{3}=D T_{s}-\left(\Delta t_{1}+\Delta t_{2}\right)
$$

Where D is switch duty cycle. $T_{s}$ is switching period of the converter.

Mode $4\left[t_{3}-t_{4}\right]$ :By making the switch off, the ampere turn of $L_{r 1}$ is transferred to $\mathrm{L}_{\mathrm{r} 2}$, and now $\mathrm{L}_{\mathrm{r} 1}$ current is equal to sum of input current $\left(\mathrm{I}_{\mathrm{in}}\right)$ and the $\mathrm{L}_{\mathrm{r} 1}$ current $\left(\mathrm{I}_{\mathrm{lr} 1}\right)$ [2]

$$
I_{L r 1} N_{1}+I_{L r 2} N_{2}=I_{1} N_{2}
$$

$$
\begin{aligned}
& {\left[I_{\text {in }}+\frac{V_{\mathrm{o}}}{n+1 Z_{r}}\right] N_{1}+\left[\frac{V_{\mathrm{O}}}{n+1 Z_{r}}\right] N_{2}=I_{1} N_{2}} \\
& I_{\text {in }} N_{1}+\frac{V_{0}}{n+1\left(Z_{r}\right)} N_{1}+\frac{V_{0}}{n+1\left(Z_{r}\right)} N_{2}=I_{1} N_{2}
\end{aligned}
$$

Where $\left(\mathrm{I}_{\mathrm{lr} 1}\right)$ is the inductor current of $\mathrm{L}_{\mathrm{r} 1}, \mathrm{I}_{\mathrm{lr} 2}$ is the inductor current of $\mathrm{L}_{\mathrm{r} 2}$ previous mode $3 . \mathrm{I}_{1}$ is current at $\mathrm{t}_{3}$. Thus by substituting equations (27) and (28) in (30).Thus the following relations are obtained.

$$
I_{1}=I_{L r 2}\left(t_{3}\right)=\frac{1}{n}\left(I_{i n}+\frac{V_{0}}{Z_{r}}\right)
$$

Thus the resonant capacitor $\mathrm{C}_{\mathrm{r}}$ charges by $\mathrm{I}_{\text {in }}$ plus. Until the capacitor voltage $\left(\mathrm{V}_{\mathrm{cr}}\right)$ reaches the output voltage $\mathrm{V}_{0}$ and the $\mathrm{L}_{\mathrm{r} 2}$ current until its voltage reaches $\mathrm{V}_{0}$. The switch voltage, $\mathrm{C}_{\mathrm{r}}$ voltage and $\mathrm{L}_{\mathrm{r} 2}$ current during this mode are [2].

$$
\begin{aligned}
& V_{s w}(t)=n+1 \quad Z_{r} \quad I_{i n}+I_{1} \sin \left(\frac{1}{n} \omega_{r} t-t_{3}\right) \\
& V_{c r} t=n Z_{r} \quad I_{i n}+I_{1} \sin \left(\frac{1}{n} \omega_{r} t-t_{3}\right) \\
& I_{L r 2} t=I_{i n}+I_{1} \cos \left(\frac{1}{n} \omega_{r} t-t_{3}\right)-I_{i n}
\end{aligned}
$$

From equation (34), switch is turned off under zero voltage switching (ZVS) condition at the beginning of this mode. Due to the leakage inductance of coupled inductor, a small voltage 
spike appear across the switch and switch voltage rises. the switch is turned off under almost zero voltage switching condition (ZVS),even though spike is much smaller than maximum switch voltage. At $\mathrm{t}_{4}, \mathrm{~V}_{\mathrm{cr}}$ capacitor voltage reaches output voltage $\mathrm{V}_{0}$. thus duration of this mode and maximum voltage stress of switch are

$$
\begin{aligned}
& \Delta t_{4}=t_{4}-t_{3}=\frac{n}{\omega_{r}} \sin ^{-1}\left(\frac{V_{0}}{V_{0}+(n+1) Z_{r} I_{i n}}\right) \\
& V_{s w, \max }=V_{s w}\left(t_{4}\right)=\left(1+\frac{1}{n}\right) V_{0}
\end{aligned}
$$

Mode $5 t_{4}-t_{5}$ : In mode5 capacitor voltage $\left(\mathrm{V}_{\mathrm{cr}}\right)$ reaches output voltage $\mathrm{V}_{0}$ and the diode $\mathrm{D}_{0}$ turns on under ZVS condition. At the starting of this mode, $L_{r 2}$ current [2] is

$I_{2}=\sqrt{\left(\frac{n+1}{n}\right)^{2} I_{i n}{ }^{2}+\frac{2(n+1) V_{0}}{n^{2} Z_{r}} I_{i n}}-I_{i n}$

In mode5, the inductor current $\left(\mathrm{L}_{\mathrm{r} 2}\right)$ current decreases linearly. Thus the $L_{r 2}$ Current equation during this mode is

$$
I_{L r 2}(t)=I_{2}-\frac{V_{\mathrm{O}}}{L_{r 2}}\left(t-t_{4}\right)
$$

At $t_{5}$, the $\left(\mathrm{L}_{\mathrm{r} 2}\right)$ current reaches zero, and therefore diode $\mathrm{D}_{1}$ turns off under ZCS condition; thus

$$
\Delta t_{5}=t_{5}-t_{1}=\frac{L_{r 2} I_{2}}{V_{0}}
$$

Mode $6\left[\mathrm{t}_{5}-\mathrm{t}_{6}\right]$ :During mode $6 \mathrm{I}_{\text {in }}$ freewheels through the diode $\mathrm{D}_{0}$ ,and the current through the resonant inductor remains zero and voltage across the resonant capacitor stays at $\mathrm{V}_{0}$. The duration of this mode is [2]

$$
\Delta t_{6}=1-D T_{s}-\Delta t_{4}+\Delta t_{5}
$$

This converter operates in continuous conduction mode (CCM) and discontinuous conduction mode(DCM) are similar. However CCM is preferred since the energy stored in leakage inductors in this condition is less than in DCM.

\section{DESIGN CONSIDERATIONS TO ACHIVE ZVS AND ZCS FOR BOOST CONVERTER}

The design of the Boost converter and Buck Boost converter circuit involves the selection of $\mathrm{C}_{\mathrm{r}}, \mathrm{L}_{\mathrm{r} 1}$ and n. $_{\mathrm{r}}$ provides ZVS condition for the switch turn off instant. Therefore its value can be selected similar to any snubber capacitor as follows, fall time $\left(t_{f}\right)$ of the switch is taken from switch data sheet of IRF840 [2].

$$
\begin{gathered}
C_{r}>C_{r, \min }=\frac{I_{s w} t_{f}}{2 V_{s w}} \\
\mathrm{Cr}=(2.77 * 3.610 * 10 \mathrm{e}-07 / 2 * 50) \\
\mathrm{Cr}=10 \text { nano farad }
\end{gathered}
$$

where $t_{f}$ is the switch current fall time, $I_{s w}$ is switch current before turnoff i.e. input current for boost and buck boost converter, and $\mathrm{V}_{\mathrm{sw}}$ is the switch voltage after turnoff i.e. input voltage for boost and buck boost converter. In practice $C_{r}$ is considered much larger than $\mathrm{C}_{\mathrm{r}, \mathrm{min}}$ to guarantee soft switching. Inductor $\left(\mathrm{L}_{\mathrm{r} 1}\right)$ provides $\mathrm{ZCS}$ condition for switch turn on instant. This inductor $\left(\mathrm{L}_{\mathrm{r} 1}\right)$ can be selected according to [2] as follows

$$
\begin{gathered}
\boldsymbol{L}_{r 1}>\boldsymbol{L}_{r, \min }=\frac{V_{s w} t_{r}}{\boldsymbol{I}_{s w}} \\
\mathrm{~L}_{\mathrm{r} 1}=(50 * 9.972 * 10 \mathrm{e}-07 / 2.77) \\
\mathrm{L}_{\mathrm{r} 1}=18 \text { micro Henry }
\end{gathered}
$$

were $t_{r}$ is the switch current rise time of the switch IRF840. In practice $\mathrm{L}_{\mathrm{r} 1}$ is considered much larger than $\mathrm{L}_{\mathrm{r} \text {,min }}$ to guarantee soft switching.

\section{GENERALIZED DESIGN PROCEDURE FOR BOOST CONVERTER}

\begin{tabular}{|c|c|}
\hline Input Voltage (Vin) & $14 \mathrm{~V}$. \\
\hline Output Voltage (Vo) & $44 \mathrm{~V}$. \\
\hline Switching Frequency $(\mathrm{SF})$ & $10 \mathrm{KHz}$. \\
\hline Ripple Current $(\Delta \mathrm{I})$ & $1.338 \mathrm{~A}$ \\
\hline Ripple Voltage $(\Delta \mathrm{V})$ & $0.0333 \mathrm{~V}$. \\
\hline Duty Ratio $(\mathrm{k})$ & 0.5 \\
\hline
\end{tabular}


To Calculate The Value Of Inductance (L):

i) $\Delta \mathrm{I}=(\operatorname{Vin} \mathrm{K} / \mathrm{f} \mathrm{L})$

Therefore $\mathrm{L}=(\mathrm{V}$ in $\mathrm{K} / \mathrm{f} \Delta \mathrm{I})$

$\mathrm{L}=(14 * 0.5 / 100001.388)$

$\mathrm{L}=500 \mu \mathrm{H}$

To Find Output Current

_Output Power $(\mathrm{Po})=\mathrm{V}_{\mathrm{o}} * \mathrm{I}_{\mathrm{o}}$

$I_{0}=(44 / 50)$

$I_{0}=0.88 A$

To Calculate The Value Of Capacitance (C):

ii) $\Delta \mathrm{Vc}=\left(\mathrm{I}_{\mathrm{o}} \mathrm{K} / \mathrm{f} \mathrm{C}\right)$

$\mathrm{C}=($ Io $\mathrm{K} / \mathrm{f} \Delta \mathrm{Vc})$

$C=(0.88 * 0.5 / 100000 * 0.0333)$

$\mathrm{C}=130 \mu \mathrm{F}$

\section{SIMULATION AND EXPERIMENTAL RESULTS FOR BOOST CONVETER}

Boost Converter Topology:

A prototype for Pulse Width Modulation soft single switched converter Boost Converter is constructed and operates at with given input voltage at $14 \mathrm{~V}$, output voltage of $44 \mathrm{~V}$.The converter operates at $10 \mathrm{KHz}$ switching frequency and an output power of 50W. The designed values of the various components are as follows. Filter inductor $(\mathrm{L})=50 \mu \mathrm{H}$, Filter Capacitor (C) $=130 \mu \mathrm{F}$, values for coupled inductor $\left(\mathrm{L}_{\mathrm{r} 1}\right)=18 \mu \mathrm{H}$, resonant capacitor $\left(\mathrm{C}_{\mathrm{r}}\right)=10 \mathrm{nF}$ and $\mathrm{n}=3$ respectively and output power of 50W. IRF 840 is selected for converter switch, and MUR460 is chosen for diodes $\mathrm{D}_{0}$ and $\mathrm{D}_{1}$. From simulation results, it is observed from the converter can be observed that the switch is turned on under ZCS and turned off at almost under ZVS condition. Due to the Phenomenon of resonance between leakage inductance of inductor and switch junction capacitor soft switching is achieved for the main switch. In the topology main diode $\mathrm{D}_{0}$ turns on under ZVS condition and turns off under ZVZCS. Current through diode $\mathrm{D}_{0}$ increases can jump from zero to $\mathrm{I}_{2}+\mathrm{I}_{\text {in }}$ and then would linearly reach to $\mathrm{I}_{\text {in }}$.

However the inductance in series with diode $D_{0}$ starts to resonante with capacitor $\left(\mathrm{C}_{\mathrm{r}}\right)$ and it causes zero voltage switching (ZVS) of the diode $\left(\mathrm{D}_{0}\right)$.After the above condition the resonance current through the diode $\left(\mathrm{D}_{0}\right)$ decreases linearly. It is observed that diode $\left(\mathrm{D}_{1}\right)$ can be turned on under zero voltage switching (ZVS) condition and turns off under zero current switching (ZCS).It can be observed converter does not require extra switch to achieve soft switching, which considerably simplifies the control circuit. However switch voltage stresses, current stresses of the switch is reduced by achieved by doing soft switching condition. The experimental results of a prototype converter were shown in figure.9-16.From experimental results it is observed that switch is turned on under zero current condition and turned off at almost zero voltage switching condition. Firing pulses for switch is provided to the microcontroller, and output dc voltage is obtained from the converter.

\subsection{Microcontroller Circuit Description}

Microcontroller has CPU (microprocessor), RAM, ROM, I/O ports, Timer ,ADC and other peripherals .Microntroller the fixed amount of on-chip ROM, RAM, and number of I/O ports makes them ideal for many applications in which cost and space are critical.

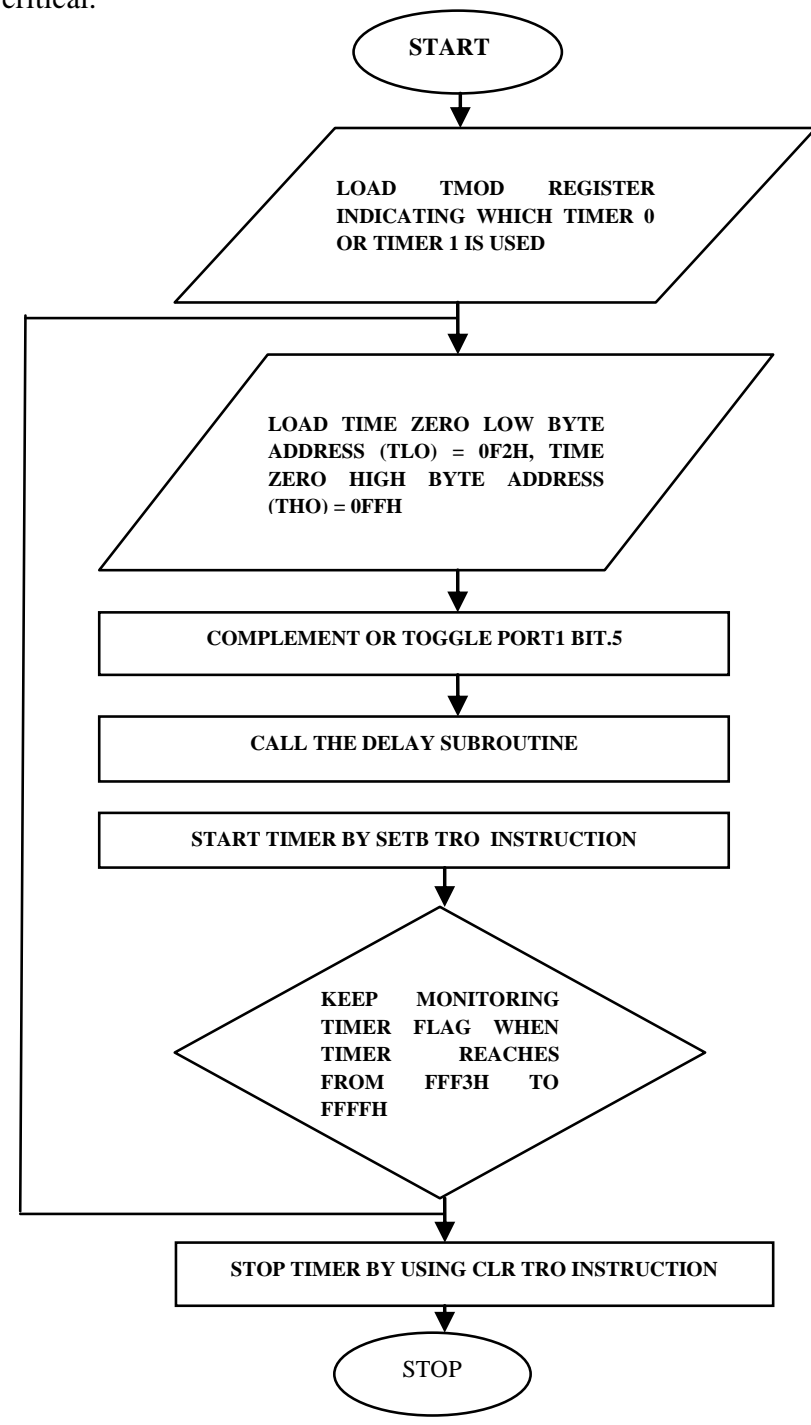

Fig 3 Flow Chart for Microcontroller 


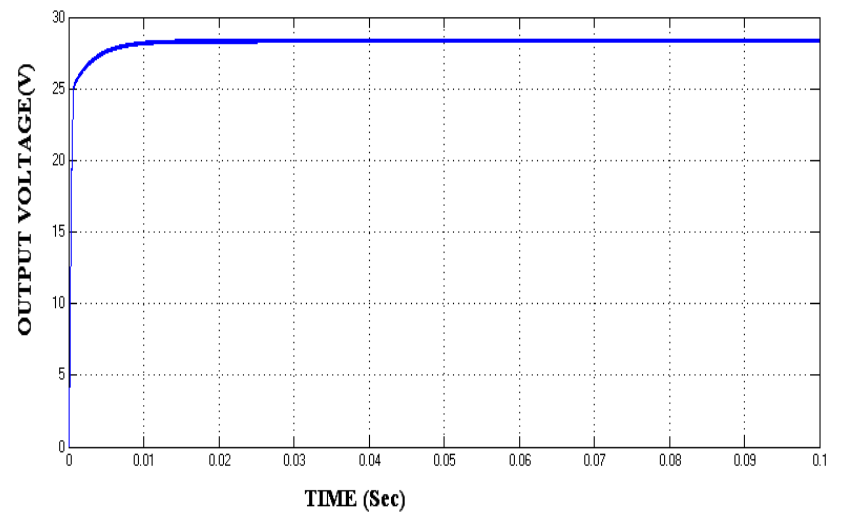

Fig.4.Output Voltage Waveform (Boost Converter)

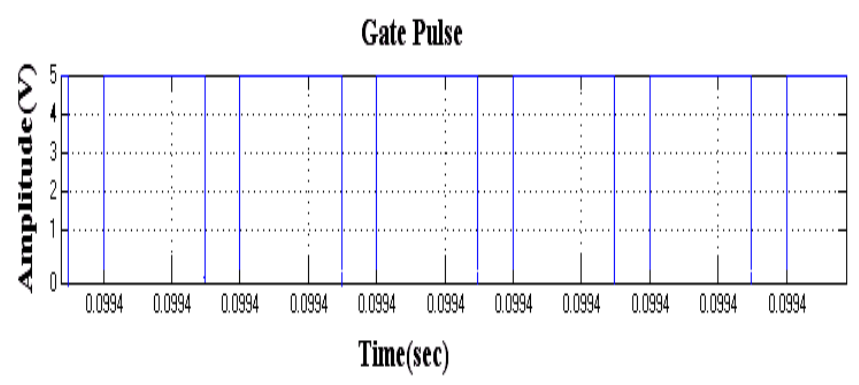

(a)

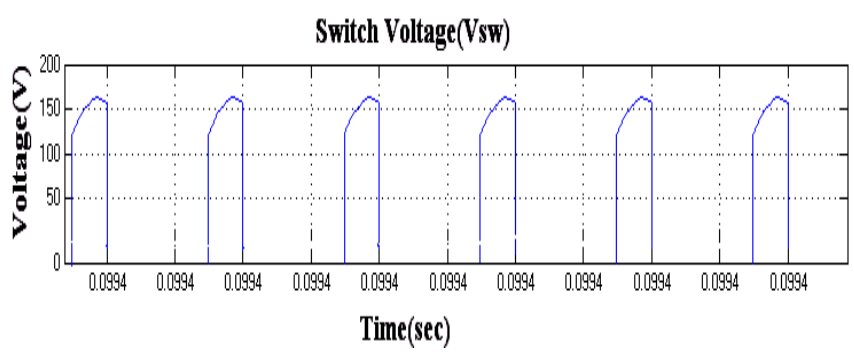

(b)

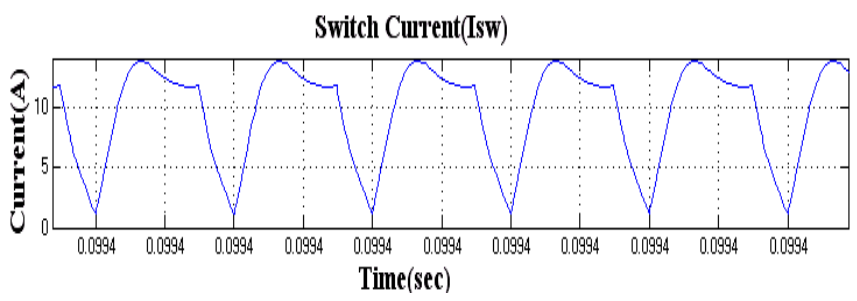

(c)

Fig. 5.(a) the switch at different switching cycle (voltage:1 V/div),(b) the switch voltage at turn on and turn off instant (50V/div ;time scale:1 $\mu \mathrm{S} / \mathrm{div})$,(c) the switch current at turn on and turnoff instant $(5 \mathrm{~A} / \mathrm{div}$;time scale: $1 \mu \mathrm{S} / \mathrm{div})$

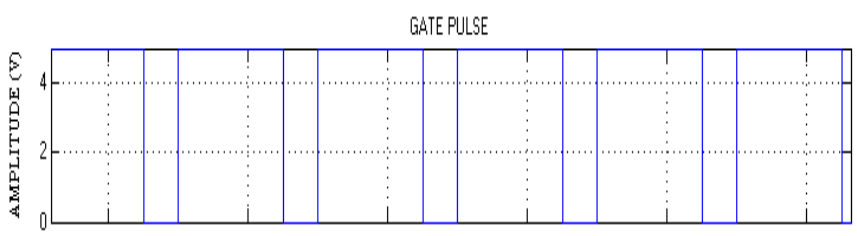

(a)

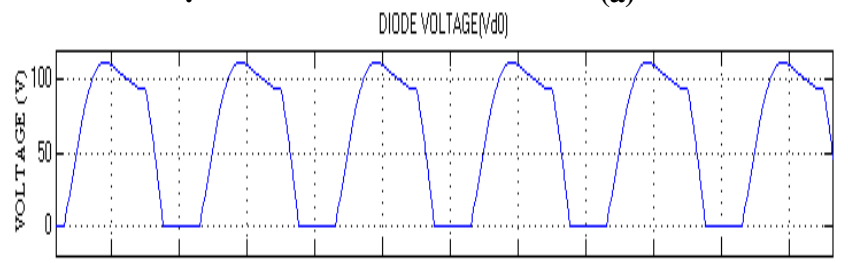

(b)

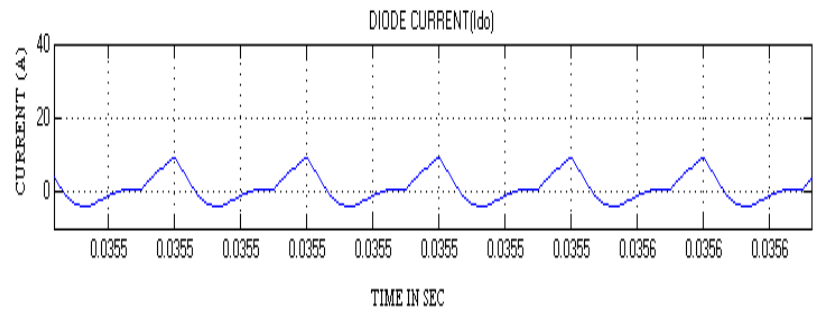

(c)

Fig. 6.(a) the switch at different switching cycle (voltage:2V/div),(b)the diode voltage $D_{0}$ at turnon and turnoff instant (50 V/div; time scale: $1 \mu s / \mathrm{div})(\mathrm{c})$ the diode current $D_{0}$ at turnon and turnoff instant $(20 \mathrm{~A} /$ div; time scale: $1 \mu S$ /div)

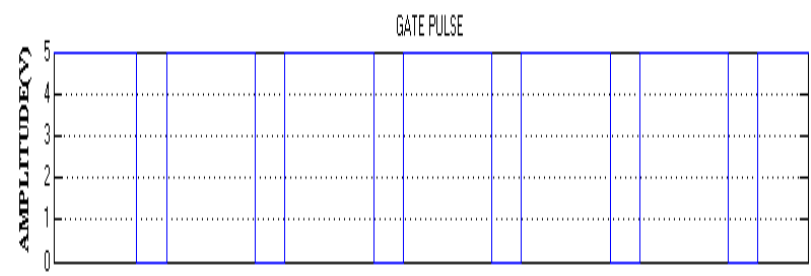

(a)

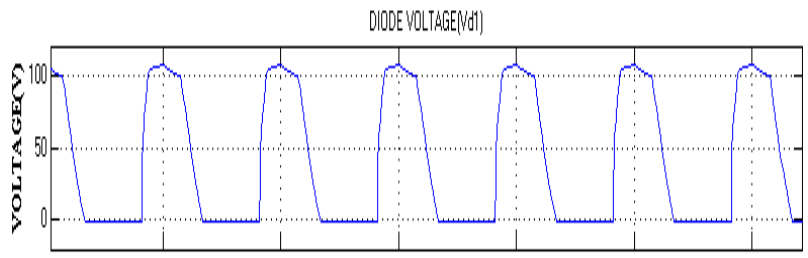

(b) 


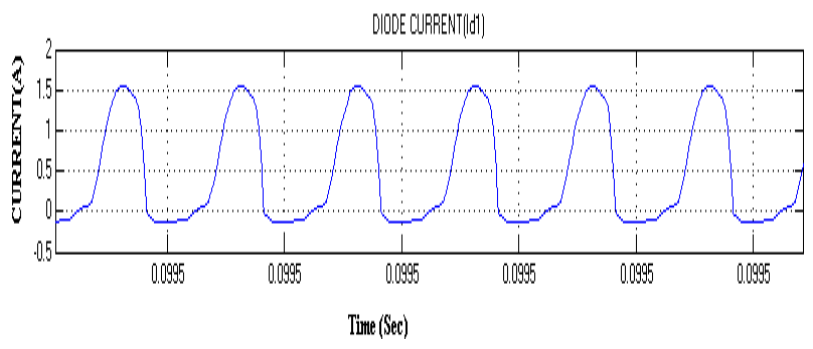

Fig.7. (a)the switch at different switching cycle (voltage: $1 \mathrm{~V} / \mathrm{div}$ ),(b)the diode voltage $\mathrm{D}_{1}$ at turnon and turnoff instant $(50 \mathrm{~V} / \mathrm{div}$; time scale: $1 \mu \mathrm{S} / \mathrm{div})(\mathrm{c})$ the diode current $D_{1}$ at turnon and turnoff instant $(0.5 \mathrm{~A} / \mathrm{div}$; time scale: $1 \mu S$ /div)

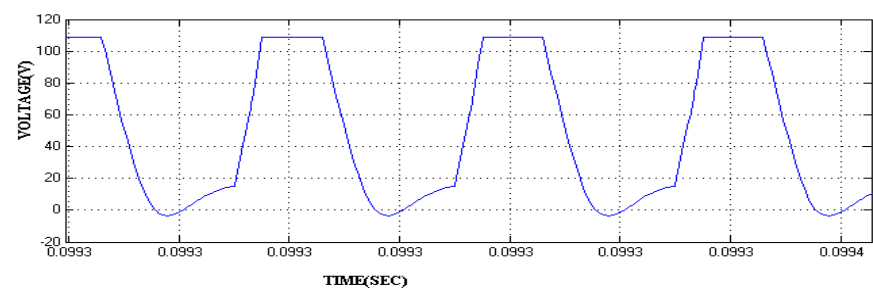

Fig.8. (a)Capacitor voltage waveform at turnon and turnoff instant of switching cycle(voltage:20 V/div; time scale:1 $\mu s$ /div)

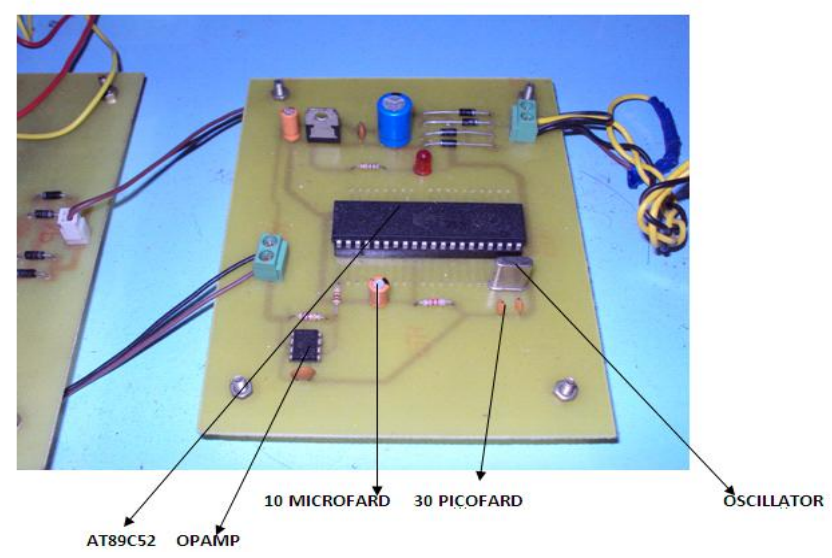

Fig 9 Complete Hardware Set Up For Microcontroller. PULSE GENERATION FROM MICROCONTROLLER

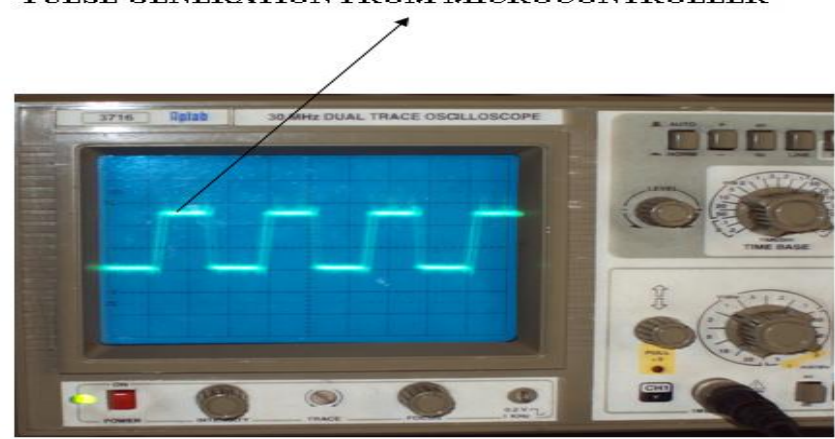

Fig.10 Firing pulses obtained from microcontroller

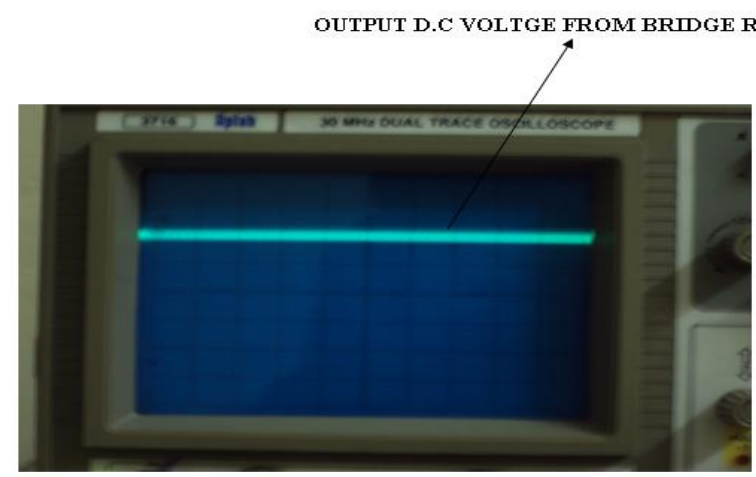

Fig .11 Output dc voltages from bridge rectifier

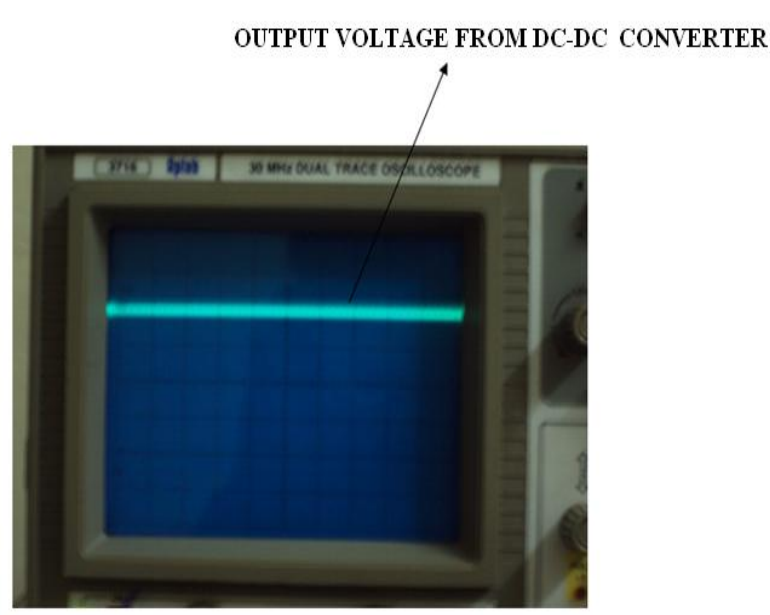

Fig .12 Output dc voltage from dc-dc converter

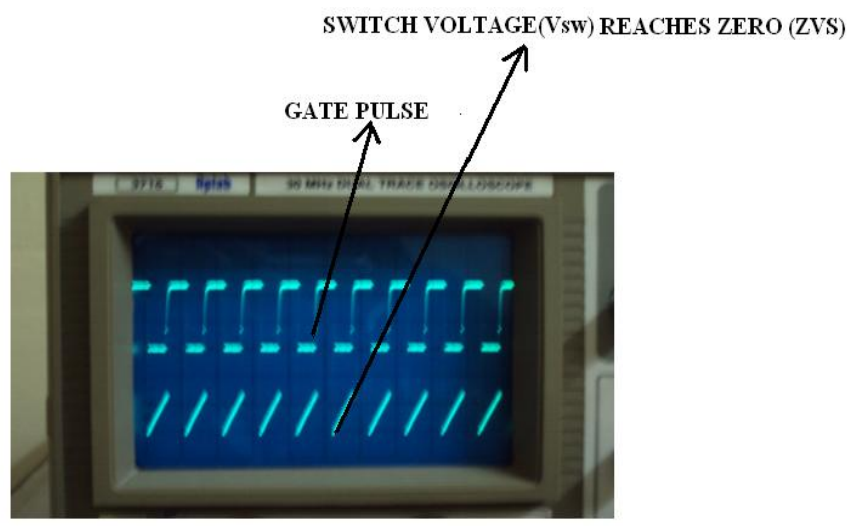

Fig.13 Zero voltage switching from switch during turn off of condition switch. 


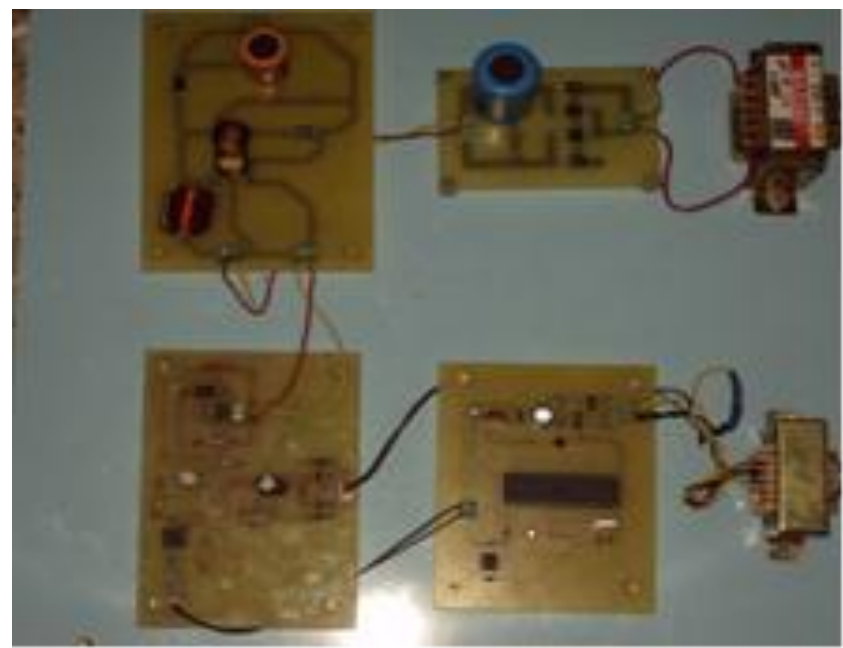

Fig 14 Complete Hardware Set Up for Soft Single Switched From Boost Converter

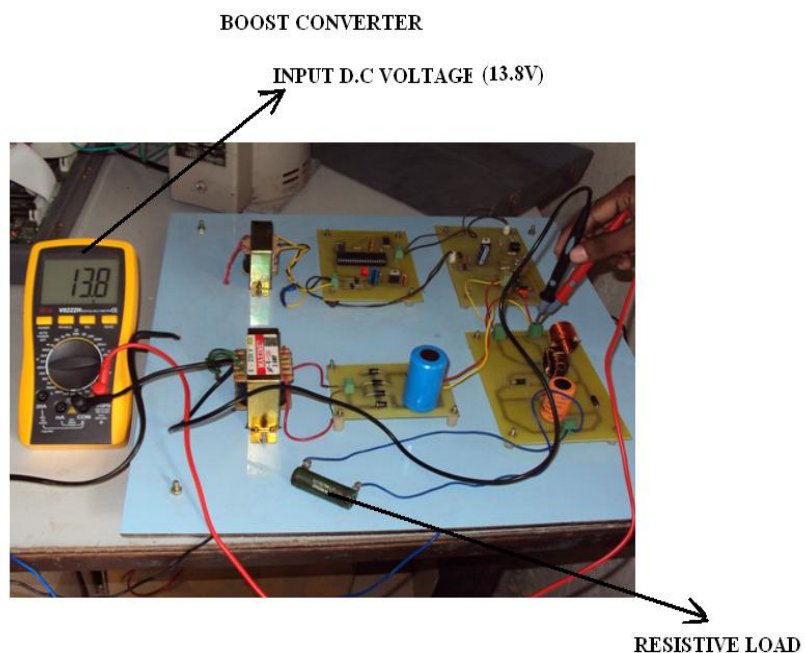

Fig 15 Input dc voltage obtained from Boost Converter. (Complete Hardware Set Up)

OUTPUT DC VOLTAGE FROM BOOST CONVERTER

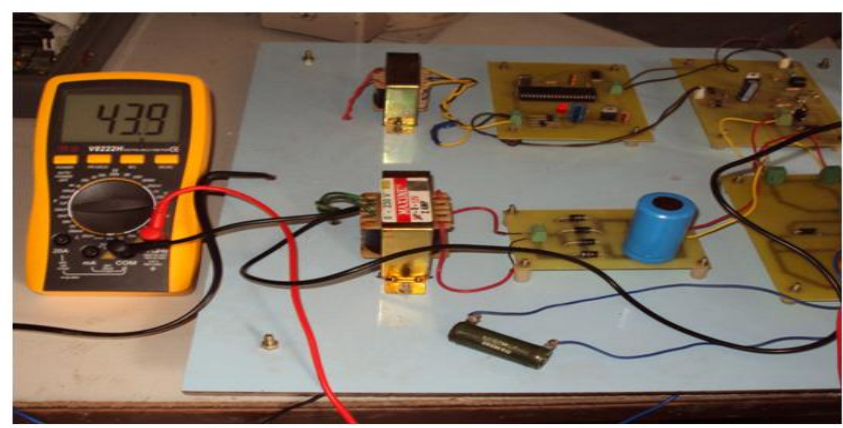

Fig 16 Output de voltage obtained from Boost Converter.(Complete Hardware Set Up)

\section{CONCLUSION}

In this paper a Prototype PWM SSS boostconverter without high voltage and current stresses has been demonstrated .These converter topology does not require extra switch to achieve soft switching which considerably simplifies the control circuit. The proposed topology can be extended to other nonisolated soft single switched dc-dc converters.

\section{REFERENCE}

[1] J. Y. Lee, G.W. Moon, H. J. Park, and M. J. Youn, "Integrated ZCS quasi resonant power factor correction converter based on fly back topology,"IEEE Trans. Power Electron., vol. 15, no. 4, pp. 634-643, Jul. 2000.

[2]. Mohammad Reza Amini, , and Hosein Farzanehfard, , “ Novel Family of PWM Soft-Single-Switched DC-DC Converters With Coupled Inductors," IEEE Trans. Power Electron., vol. 56, no. 4, pp. 635-638, Jul. 2009.

[3] S. S. Lee and G.W.Moon, "Full ZVS-range transient current buildup half bridge converter with different ZVS operations to load variation," IEEE Trans. Ind. Electron., vol. 55, no. 6, pp. 2557-2559, Jun. 2008.

[4] E. Adib and H. Farzanehfard, "Family of zero-current transition PWM Converters," IEEE Trans. Ind. Electron., vol. 55, no. 8, pp. 3055-3063,Aug. 2008.

[5] J. L. Russi, M. L. D. S. Martins, L. Schuch, J. R. Pinheiro, and H. L. Hey,"Synthesis methodology for multipole ZVT converters," IEEE Trans. Ind.Electron., vol. 54, no. 3, pp. 1783-1795, Mar. 2007.

[6] E. Adib and H. Farzanehfard, "Family of isolated zerovoltage transition PWM converters," IET Power Electron. vol. 1, no. 1, pp. 144-153, Mar. 2008.

[7] T. F. Wu, Y. S. Lai, J. C. Hung, and Y. M. Chen, "Boost converter with coupled inductors and buck-boost type of active clamp," IEEE Trans. Ind.Electron. vol. 55, no. 1, pp. 154-162, Jan. 2008.

[8] X. Wu, J. Zhang, X. Ye, and Z. Qian, "Analysis and derivations for a family ZVS converter based on a new active clamp ZVS cell," IEEE Trans. Ind. Electron. vol. 55, no. 2, pp. 699-710, Feb. 2008.

[9] J.-J. Lee, J.-M., E.-H. Kim and B.-H. Kwon, "Dual seriesresonant active-clamp converter," IEEE Trans. Ind. Electron., vol. 55, no. 2, pp. 699-710, Feb. 2008.

[10] L. R. Barbosa, J. B. Vieira, L. C. Freitas, M. S. Vilela, and V. J. Farias "A buck quadratic PWM soft-switching converter using a single active switch," IEEE Trans. Power Electron., vol. 14, no. 3, pp. 445-453, May 1999.

[11] E. S. da Silva, L. R. Barbosa, J. B. Vieira, L. C. Freitas, and V. J. Farias, "An improved boost PWM soft-singleswitched converter with low voltage and current stresses," IEEE Trans. Ind. Electron., vol. 48,no. 6, pp. 1174-1179, Dec. 2001.

[12] J. K. Chung and G. H. Cho, "A new soft recovery PWM quasi-resonant converter with a folding snubber network," 
IEEE Trans. Ind. Electron., vol. 49, no. 2, pp. 456-461, Apr. 2002.

[13] E. S. da Silva, E. A. A. Coelho, L. C. Freitas, J. B. Vieira, and V. J. Farias, "A soft-single-switched forward converter with low stresses and two derived structures," IEEE Trans. Power Electron., vol. 19, no. 2, pp. 388-395, Mar.2004.

[14] J. M. Kwon, W. Y. Choi, and B. H. Kwon, "Cost-effective boost converterwith reverse-recovery reduction and power factor correction," IEEE Trans. Ind. Electron., vol. 55, no. 1, pp. 471-473, Jan. 2008.

[15] K. Fujiwara and H. Nomura, "A novel lossless passive snubber for soft switching boost-type converters," IEEE Trans. Power Electron., vol. 14, no. 6, pp. 1065-1069, Nov. 1999.

[16] P. Das and G. Moschopoulos, "A comparative study of zero-current transition PWM converters," IEEE Trans. Ind. Electron., vol. 54, no. 3,pp. 1319-1328, Mar. 2007

[17] T. F. Wu and S. A. Liang, "A systematic approach to developing single stage soft switching PWM converters,"
IEEE Trans. Power Electron., vol. 16, no. 5, pp. 581-593, Sep. 2001

[18] N. Mohan, T. M. Undeland, and W. P. Robbins, Power Electronics, 3rd ed.New York: Wiley, 2003, pp. 682-690.

\section{BIOGRAPHICAL NOTES}

P.Hemachander is a is Lecturer in the Department of Electrical and Electronics Engineering, Rajiv Gandhi Engineering College, Pondicherry University, Pondicherry, India

Dr.P.Ajay-D-Vimal Raj is Assistant Professor in the Department of Electrical and Electronics Engineering, Pondicherry Engineering College, Pondicherry University, Pondicherry, India

Dr.M.Sudhakar is Associate professor in the department of Electrical \& Electronic Engineering Pondicherry Engineering College, Pondicherry University, Pondicherry, India 